\title{
KESEHATAN KERJA PADA INDUSTRI RUMAH TANGGA “ACCESORIS BURUNG” DI RT 13 RW 09 BABAKAN SARI, KIARACONDONG BANDUNG
}

https://doi.org/10.33024/jkpm.v4i6.5022

\author{
Iwan Shalahuddin ${ }^{1}$, Citra Windani Mambang Sari², Iqbal Pramukti ${ }^{3}$ \\ ${ }^{1}$ Fakultas Keperawatan Universitas Padjadjaran Kampus Garut \\ ${ }^{2}$ Fakultas Keperawatan Universitas Padjadjaran Kampus Utama \\ ${ }^{3}$ Fakultas Keperawatan Universitas Padjadjaran Kampus Utama
}

Disubmit: 01 September 2021 Diterima: 04 September 2021 Diterbitkan: 01 Desember 2021

Email Korespondensi: shalahuddin@unpad.ac.id

\begin{abstract}
ABSTRAK
Keselamatan dan kesehatan kerja (K3) merupakan sistem yang melindungi pekerja, perusahaan, lingkungan hidup, dan masyarakat sekitar dari bahaya akibat kecelakaan kerja. Keselamatan dan kesehatan pemilik serta pegawai saling berhubungan erat dengan keefektifan kerja, sehingga sangat penting sekali untuk dijaga dan dipelihara. Penerapan keselamatan dan kesehatan kerja sangat penting khususnya pada perusahaan yang berkaitan secara langsung dengan bidang produksi. Aksesoris Sangkar Burung Kiara G.357 merupakan salah satu usaha home industri, dimana usaha tersebut beroprasi sejak tahun 1990 an hingga saat ini. Kondisi pandemi Covid-19 ini juga tidak memudarkan semangat pemilik beserta karyawan pengelolanya untuk terus produktif menjalankan usaha tersebutn. Tujuan kegiatan adalah memberikan edukasi untuk Menjelaskan tentang kesehatan dan keselamatan kerja khususnya penggunaan APD dalam upaya mencegah resiko kerja di home industri. Metode yang digunakan dalam kegiatan ini adalah melalui pemutaran video, ceramah, dan diskusi serta tanya jawab. Hasil yang dicapai setelah dilakukan pendidikan kesehatan melalui penyuluhan, para peserta menyatakan dapat mengetahui dan memahami serta mengungkapkan kembali tentang kesehatan dan keselamatan kerja khususnya penggunaan APD dalam upaya mencegah resiko kerja di home industri.
\end{abstract}

Kata Kunci: APD, Home Industri, Kesehatan Keselamatan Kerja

\begin{abstract}
Occupational safety and health (K3) is a system that protects workers, companies, the environment, and the surrounding community from the dangers of work accidents. The safety and health of owners and employees are closely related to work effectiveness, so it is very important to protect and maintain them. The application of occupational safety and health is very important, especially in companies that are directly related to the production sector. Kiara G.357 Bird Cage Accessories is one of the home industry businesses, where the business has been operating since the 1990s until now. The condition of the Covid-19 pandemic has also not dampened the enthusiasm of the owners and
\end{abstract}


their managing employees to continue to be productive in running the business. The purpose of the activity is to provide education to explain occupational health and safety, especially the use of PPE in an effort to prevent work risks in the home industry. The method used in this activity is through video screenings, lectures, and discussions as well as questions and answers. The results achieved after health education was carried out through counseling, the participants stated that they could know and understand and reveal again about occupational health and safety, especially the use of PPE in an effort to prevent work risks in the home industry.

Keywords: PPE, Home Industry, Occupational Health

\section{PENDAHULUAN}

Keselamatan dan kesehatan kerja pada umumnya didefinisikan sebagai suatu pemikiran dan upaya untuk menjamin keutuhan dan kesempurnaan baik fisik maupun rohani dari tenaga kerja. Keselamatan kerja merupakan keselamatan yang berkaitan dengan mesin, alat kerja, bahan dan proses pengolahan, landasan tempat kerja dan lingkungannya, serta cara-cara melakukan pekerjaan (Kemenkes, 2016). Sedangkan yang dimaksud dengan kesehatan kerja dapat digambarkan sebagai suatu kondisi fisik, mental dan sosial seseorang yang tidak saja berada pada kondisi terbebas dari penyakit atau masalah kesehatan melainkan juga menunjukkan kemampuan untuk berinteraksi dengan lingkungan dan pekerjaannya. Kesehatan kerja bertujuan agar pekerja memperoleh derajat kesehatan baik fisik, mental maupun sosial dengan menerapkan usaha-usaha preventif dan kuratif terhadap penyakit atau gangguan kesehatan yang disebabkan oleh faktor pekerjaan dan lingkungan kerja (Kemenkes, 2016).

Penerapan keselamatan dan kesehatan kerja sangat penting sebagai upaya pencegahan kecelakaan kerja di lingkungan kerja. kerja merupakan hal yang penting bagi perusahaan, karena dampak kecelakaan dan penyakit kerja tidak hanya merugikan karyawan, tetapi juga perusahaan baik secara langsung maupun tidak langsung Kesehatan kerja dalam keperawatan atau yang biasa disebut dengan occupational healthnurse memiliki tujuan untuk membuat tenaga kerja selalu sehat, selamat, dapat bekerja secara produktif, sejahtera, memiliki daya saing yang tinggi, sehingga tenaga kerja tidak ada yang sakit ataupun dalam kondisi yang tidak sehat dan menjadikan tenaga kerja tersebut dapat bekerja secara produktif, serta tidak terjadi kecelakaan kerja yang dapat mengganggu kegiatan produksi dalam pekerjaan (Kurniawidjaja, 2010).

Menurut Bangun Wilson (2012) Keselamatan Kerja adalah perlindungan atas keamanan kerja yang dialami pekerja baik fisik maupun mental dalam lingkungan pekerjaan. Menurut Mondy dan Noe, dalam (Pangabean Mutiara, 2012), Manajemen Keselamatan kerja meliputi perlindungan karyawan dari kecelakaan di tempat kerja sedangkan, kesehatan merujuk kepada kebebasan karyawan dari penyakit secara fisik maupun mental.

Menurut Widodo (2015: 244), "Kesehatan kerja adalah suatu kondisi kesehatan yang bertujuan agar masyarakat pekerja memperoleh derajat kesehatan setinggi-tingginya, baik jasmani, rohani, maupun sosial dengan usaha pencegahan dan pengobatan terhadap penyakit atau gangguan kesehatan yang disebabkan oleh pekerjaan dan lingkungan kerja maupun penyakit umum. Kesehatan kerja merupakan suatu hal yang penting dan 
perlu diperhatikan oleh pihak perusahaan. Karena dengan adanya kesehatan yang baik maka akan menguntungkan para karyawan secara material, karena karyawan akan bekerja dengan lingkungan yang lebih menyenangkan, sehingga secara keseluruhan karyawan akan mampu bekerja lebih lama.

Di daerah RT 13 RW 09 Kelurahan Babakan Sari, terdapat beberapa masyarakat yang membuka usaha dalam bidang industri rumah tangga salah satunya seperti penjual aksesoris sangkar burung yang diberi nama Kiara G.357 Aksesoris Sangkar Burung, dimana usaha tersebut beroprasi sejak tahun 1990 an hingga saat ini. Kondisi pandemi Covid-19 ini juga tidak memudarkan semangat pemilik beserta karyawan pengelolanya untuk terus produktif menjalankan usaha tersebut. Adanya perubahan situasi seperti pandemic dan kemungkinan timbulnya kecelakaan kerja dimana notabene usaha ini membutuhkan keterampilan yang berkaitan dengan pengoperasian mesin dan benda tajam lainnya menjadi kemungkinan potensi yang patut untuk diwaspadai. Maka dari itu, kami memutuskan untuk melakukan pengkajian dan intervensi kesehatan kerja untuk alasan dapat mengatasi permasalahan kerja maupun meningkatkan pengelolaan potensi kerja yang selama ini dirasakan oleh pekerja. Adanya pemerhatian terkait kesehatan individu dan lingkungan kerja yang terjaga diharapkan dapat meningkatkan status kesehatan kerja yang juga dapat dijadikan pondasi untuk mempertahankan eksistensi usaha tersebut.

Perawat kesehatan kerja memberikan program dan layanan kesehatan dan keselamatan kepada pekerja. Area praktik khusus ini berfokus pada promosi dan pemulihan kesehatan, 2 pencegahan penyakit dan cedera, perlindungan dari bahaya terkait pekerjaan dan lingkungan, dan profitabilitas perusahaan (American Association of Occupational Health Nurses, 2017).

Menurut Widodo (2015), “Kesehatan dan keselamatan kerja (K3) adalah bidang yang terkait dengan kesehatan, keselamatan, dan kesejahteraan manusia yang bekerja di sebuah institusi maupun lokasi proyek. Menurut (Depnakes: 2005), Keselamatan dan Kesehatan Kerja adalah segala daya upaya pemikiran yang dilakukan dalam rangka mencegah, menanggulangi dan mengurangi terjadinya kecelakan dan dampak melalui langkah-langkah identifikasi, analisis dan pengendalian bahaya dengan menerapkan pengendalian bahaya secara tepat dan melaksanakan perundang- undangan tentang Keselamatan dan Kesehatan Kerja.

\section{MASALAH}

Keselamatan kerja bertalian dengan kecelakaan kerja yaitu kecelakaan yang terjadi di tempat kerja atau dikenal dengan istilah kecelakaan industri. Suatu kejadian atau peristiwa tertentu ada sebab musababnya, demikian pula kecelakaan industri/kecelakaan kerja. ada 4 (empat) faktor penyebab terjadinya kecelakaan kerja yaitu: Faktor Manusianya Misalnya karena kurangnya keterampilan atau kekurangannya pengetahuan, salah penempatannya; Faktor Materialnya/Bahannya/Peralatannya Misalnya bahan yang seharusnya terbuat dari besi, akan tetapi supaya lebih murah dibuat dari bahan lainnya sehingga dengan mudah dapat menimbulkan kecelakaan; Faktor Bahaya/Sumber Bahaya Faktor bahaya/sumber bahaya timbul karena 2 (dua) sebab, yaitu: Perbuatan berbahaya; misalnya karena metode kerja yang salah, keletihan/kelesuan, sikap kerja yang tidak sempurna dan sebaginya; Kondisi/keadaan berbahaya yaitu keadaan yang tidak aman dari 
mesin/peralatan-peralatan, lingkungan, proses, sifat pekerjaan; Faktor yang Dihadapi Misalnya kurangnya pemeliharaan/perawatan mesinmesin/peralatan sehingga tidak bisa bekerja dengan sempurna.

Keselamatan dan Kesehatan Kerja pada home industry sangat penting untuk dipersiapkan agar terhindarnya dari bahaya atau kecelakaan yang mungkin saja terjadi. Kecelakaan dapat terjadi akibat kelalaian dari perusahaan, pekerja, maupun keduanya, dan akibat yang ditimbulkan dapat memunculkan trauma bagi kedua pihak. Bagi pekerja, cedera akibat kecelakaan dapat berpengaruh terhadap kehidupan pribadi, kehidupan keluarga, dan kualitas hidup pekerja tersebut. Sedangkan bagi perusahaan, kerugian produk dan waktu yang terbuang karena penyelidikan atas kecelakaan tersebut, serta biaya untuk melakukan proses hukum atas keselamatan kerja.

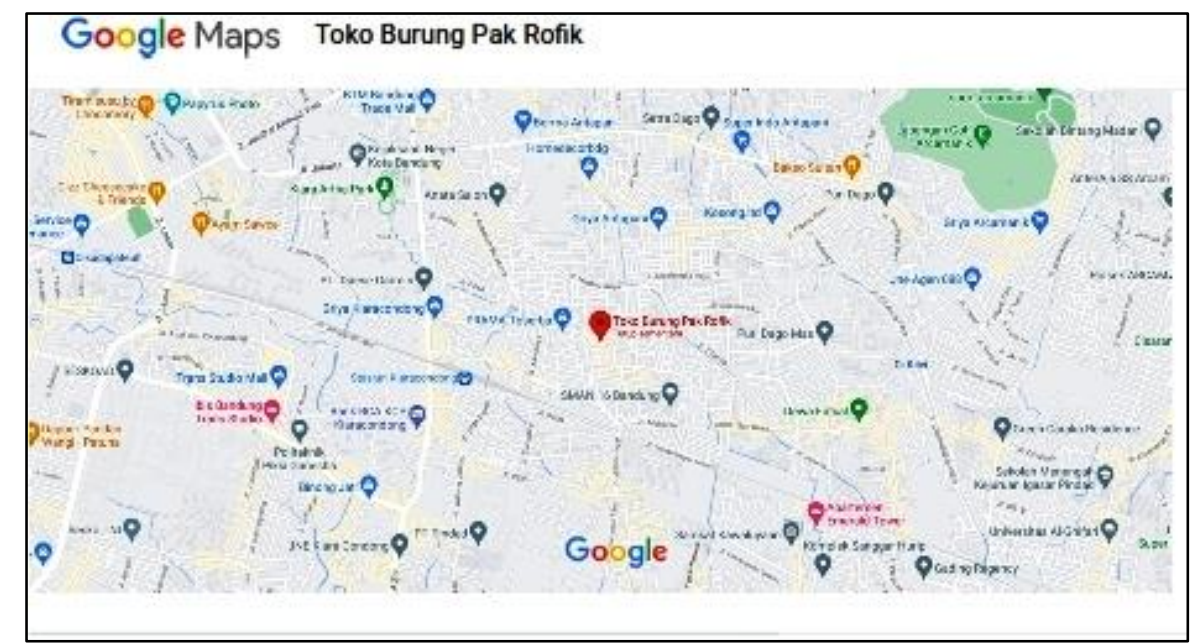

Gambar 1: Lokasi Home Industri Kiara G.357 Aksesoris Sangkar Burung Babakan Sari Kiara Condong Bandung

\section{METODE.}

Subjek dalam pengabdian ini sasarannya adalah para pekerja dan pemilik home industry kiara teknik Accesoris Burung. Dengan jumlah peserta yang mencapai 20 orang ,maka metode group/kelompok besar ini cocok diterapkan dalam kegiatan pemberian pendidikan dan promosi kesehatan dengan bentuk edukasi. Tahap persiapan melakukan koordinasi dengan Babakan Sari Kiaracondong dan Kelurahan Babakan Sari untuk permohonan izin kegiatan, identifikasi mengenai keadaan umum, pengetahuan, perilaku serta upaya pelaksanan K3 dalam pekerjaan dan Mempersiapkan sumber daya yang dibutuhkan yang melibatkan mahasiswa Fakultas Keperawatan yang sedang melaksanakan Kegiatan profesi keperawatan Komunitas di daerah tersebut.

Metode yang dilakukan dalam pendidikan kesehatan adalah penjelasan atau ceramah yang diberikan oleh pemateri kepada pekerja dan pemilik home industry kiara teknik Accesoris Burung secara virtual, dan diikiuti dengan tanya jawab, pemateri harus memastikan semua pekerja mengerti materi yang telah disampaikan 
dengan memastikan kembali kepada peserta apabila ada hal-hal yang kurang jelas. Melakukan Pre Test tentang Resiko Cedera melalui pertanyaan secara lisan dan Melaksanakan penyuluhan kesehatan pentinggnya upaya melakukan Pengelolaan resiko cedera yang baik dan benar selama melaksanakan pekerjaan agar terhindar dari gangguan kesehatan dan gangguan keselamatan kerja. Media informasi bagi pekerja ini disusun oleh tim pengabdian pada masyarakat yang bekerjasama dengan mahasiswa serta melakukan Post Test melalui pertanyaan secara lisan.

\section{HASIL DAN PEMBAHASAN}

Hasil pengkajian didapatkan bahwa Kiara Teknik yang dipimpin oleh pak Ujang rahman dengan asistennya pak andi juandi merupakan salah satu home industri informal yang ada di Wilayah RW 09 RT 13 Desa Babakan Sari Kelurahan Kiara Condong. yang pertama kali didirikan oleh Pak Ujang rahman. Home Industri kiara teknik ini memiliki 20 orang pegawai. Luas bangunan Kiara teknik ini sekitar 12x8 $\mathrm{m}^{2} 94 \mathrm{~m} 2$ dan bangunan berbentuk persegi panjang. Lokasi bangunan produksi berada di sekitar pemukiman warga, mudah dijangkau dan strategis. Home Industry ini bisa dikatakan tidak terlalu menghasilkan limbah yang berbahaya bagi kesehatan masyarakat sekitar. Pengelolaan Limbah pada home industry, menurut Tn.A mengatakan bahwa industri ini tidak mengeluarkan limbah yang berbahaya karena tidak menggunakan bahan kimia. Limbah yang dihasilkan dari industri ini yaitu kaleng dan perusahaan sudah menyediakan tempat khusus untuk pembuangan limbah.

Home Industri kiara teknik ini tidak ada biaya ataupun dana yang diperuntukkan bagi kesehatan pekerjanya seperti asuransi namun bergantung pada bpjs masing-masing pekerja. Selama 3 bulan didirikan Industri ini, tidak pernah ada pegawai yang sakit parah hanya sakit ringan seperti demam, flu, batuk biasa. Namun, pernah ada kejadian kecelakaan kerja akibat mesin pon pada salah satu pekerja. Pada masa pandemic Covid19 ini perusahaan menyediakan tempat cuci tangan beserta sabun untuk para pegawai digunakan oleh pegawai ketika sebelum dan sesudah bekerja. Di home industri ini juga sudah dilakukan penyuluhan khusus terkait Covid-19 yang ditujukan ke pegawai melalui poster.

Pada masa pandemic Covid-19 ini perusahaan mewajibkan pegawai untuk memakai masker. Di industri ini terdapat kotak P3K yang di dalamnya terdapat seperti betadin, Kayu putih, Perban, Sarung tangan, Obat. Kemungkinan penyebab terjadinya kecelakaan kerja berasal dari kecerobohan para pekerja/melamun sehingga jadi terluka. Sumber kecelakaan kerja terdekat yang mengancam adalah resiko cedera tangan terjepit karena mengoprasikan mesin pon, tergores besi dan seng serta cedera karena menggangkat barang yang lumayan beratnya. Akan tetapi perusahaan sudah melakukan pencegahan yaitu dengan selalu mengingatkan para pegawai agar selalu hati hati dan selalu istirahat dengan maksimal pada jam istirahat serta merujuk kerumah sakit secepatnya ketika ada pekerja yang mengalami kecelakaan kerja

Berdasarkan hasil wawancara kepada pegawai didapatkan hasil bahwa diantara semua pegawai tidak ada yang mengalami tanda dan gejala dari Covid-19 dan semua pegawai tinggal di Desa yang sama. Para pegawai juga 
mengatakan tidak khawatir walaupun masih harus bekerja di tengah wabah Covid-19 karena sudah menerapkan protokol kesehatan dan upaya pencegahan seperti memakai masker dan cuci tangan. Namun tidak ada aturan khusus dari tempat bekerja dalam menerima tamu selama COVID-19, serta tempat bekerja tidak menyediakan rapid test atau swab untuk para pegawai

Selama bekerja, seluruh pegawai ada yang memakai alat pelindung diri ada yang tidak contohnya memakai masker. Penyediaan alat P3K juga tidak ada, jika ada pekerja yang sakit atau mengalami kecelakaan selama bekerja mereka berobat secara mandiri, dan semua pegawai tidak ada yang memiliki jaminan kesehatan

Berdasarkan hasil rekapitulasi hasil pengkajian kebutuhan belajar dapat terlihat bahwa ada sebagian pekerja, kebutuhan belajar yang termasuk kedalam kebutuhan belajar : Perceived needs Karena ada sebagian mengetahui dampak dari penggunaan APD yang tidak baik dan tidak benar bagi pekerja; Unperceived needs Karena ada sebagian pekerja tidak melakukan pencegahan resiko kerja dengan penggunaan APD yang baik dan benar yang berbahaya bagi kesehatan; Misperceived needs Karena ada sebagian peserta yang mengetahui bahaya jika tidak melakukan pencegahan resiko kerja dengan penggunaan APD yang baik dan benar yang berbahaya bagi kesehatan, tetapi masih ada kebiasaan yang tidak mengetahui cara melakukan upaya-upaya pencegahan gangguan kesehatan dan keselamatan kerja dari unsur penggunaan APD dalam beraktifitas kerja. Data Rekapitulasi Hasil Pengkajian Kebutuhan Belajar Jumlah audience : 20 orang, Audience terdiri dari para pekerja dari seluruh bagian dalam proses pembuatan Accesoris sangkar burung.

Kegiatan pendidikan kesehatan yang dilaksanakan pada hari selasa, 26 Januari 2021 jam 09.00 - selesai WIB, dilakukan secara virtual melalui aplikasi google meeting. Kegiatan ini dimulai dengan pembukaan oleh MC, lalu sambutan. Kegiatan diawali dengan MC menanyakan sejauh mana peserta mengetahui tentang penggunaan APD dalam bekerja, apakah peserta pernah mengalami gangguan kesehatan akibat tidak menggunakan APD yang bena terutama resiko dalam bekerja, dan dampak apa saja yang akan muncul apabila tidak melakukan upaya pencegahan tersebut. Dari semua jawaban peserta, peserta cukup mengenal dengan bahaya dari tidak melakukan upaya melakukan pencegahan resiko kerja dengan penggunaan APD yang baik dan benar, namun peserta masih belum paham mengenai dampak apa saja yang akan timbul pada pekerja yang mengalami kebiasaan tidak melakukan memperhatikan pencegahan resiko kerja dengan penggunaan APD yang baik dan benar. Kemudian peserta diberi pre test melalui google form untuk mengetahui sejauh mana pengetahuan nya sebelum materi disampaikan oleh pemateri.

Kegiatan dilanjutkan dengan pemberian materi menggunakan PPT dan penampilan video yang sudah disiapkan, agar peserta tetap tertarik untuk mengikuti acara dan tidak bosan. Materi yang disampaikan ialah mengenai tentang penggunaan APD yang baik dan benar dalam upaya pencegahan resiko kerja. Pemberian materi diawali dengan materi inti, pemateri langsung menampilkan PPT yang sudah disiapkan. Saat sesi pematerian berjalan dengan lancar dan peserta tampak fokus dan menyaimak apa yang sedang dipresentasikan. Setelah materi selesai disampaikan, dilanjut dengan penayangan video tentang penggunaan APD yang baik dan benar pada saat bekerja yang disertai dengan gerakan peregangan dan selanjutnya sesi tanya 
jawab yang bertujuan untuk mengetahui sejauh mana perubahan pekerja dari yang sebelumnya dan sesudahnya diberikan penkes. Pertanyaan dibacakan oleh pemateri dan peserta antusias untuk menjawab pertanyaan, total ada 5 pertanyaan yang dijawab semua dengan benar oleh beberapa orang peserta.

Sebelum dilakukan pendidikan kesehatan, peserta didik yaitu pegawai dan pemilik home industry diberikan terlebih dahulu link pre test dan setelah pendidikan kesehatan diberikan link post test sebagai evaluasi pembelajaran. Berkoordinasi dengan pemilik home industry untuk memantau keselamatan dan kesehatan pekerja, memfollow up kepada pemilik atau pegawai dalam keseharian terkait materi yang telah disampaikan, meminta kesediaan pegawai untuk menyebar e-poster pada pegawai yang tidak ikut berpartisipasi dalam pendidikan kesehatan, dan memberikan poster edukasi dalam bentuk fisik ke pemilik home industry untuk dipasang ditempat kerja.

Evaluasi penyuluhan mengenai penggunaan APD yang Baik dan Benar Saat Bekerja dalam upaya pencegahan resiko kerja, dilaksanakan secara virtual dengan jumlah peserta kurang lebih 20 peserta. Peserta penyuluhan terlihat antusias saat pemberian materi berlangsung. Peserta mengikuti penyuluhan dengan senang hati karena penyuluhan dilaksanakan dengan menyenangkan. Kegiatan penyuluhan berjalan kondusif karena peserta memperhatikan materi yang disampaikan dengan baik. Hal ini dibuktikan dengan banyaknya peserta yang tertarik untuk menjawab pertanyaan ketika sesi tanya jawab.

Efektifnya fungsi media ajar yang digunakan dapat terlihat jelas oleh seluruh peserta. Karena penyuluhan dilakukan secara virtual sehingga para peserta tidak perlu harus berbondong bondong hadir ke suatu tempat, teteapi cukup hanya dengan menyimak dari virtual di tempat tinggalnya dan tempat kerjanya masing-masing. Hal ini dapat menjadikan keefektifan penjelasan materi. Respon peserta yang baik terlihat dengan antusias untuk mengikutinya dari awal hingga akhir kegiatan.

Kegiatan ini dilaksanakan melalui penyuluhan online, yaitu dengan kuliah lewat google meeting. Kuliah ini dilakukan sesuai dengan rencana yang telah disusun. Upaya yang dilakukan merupakan bagian dari upaya pencegahan (preventif) dan pendidikan kesehatan (promotif) dalam upaya mencegah terjadinya gangguan kesehatan dan keselamatan akibat resiko kerja.Pelaksanaan penyuluhan ini tidak mendapatkan hambatan yang berarti, hal ini dikarenakan sebelumnya sudah merundingkan kerjasama dan koordinasi yang baik dengan pihak Puskesmas dan pihak Desa Babakan Sari Kiara Condong Bandung juga pihak pemilik home industri, sehingga sangat mudah untuk mengerahkan karyawanya untuk mengikuti penyuluhan tersebut. 

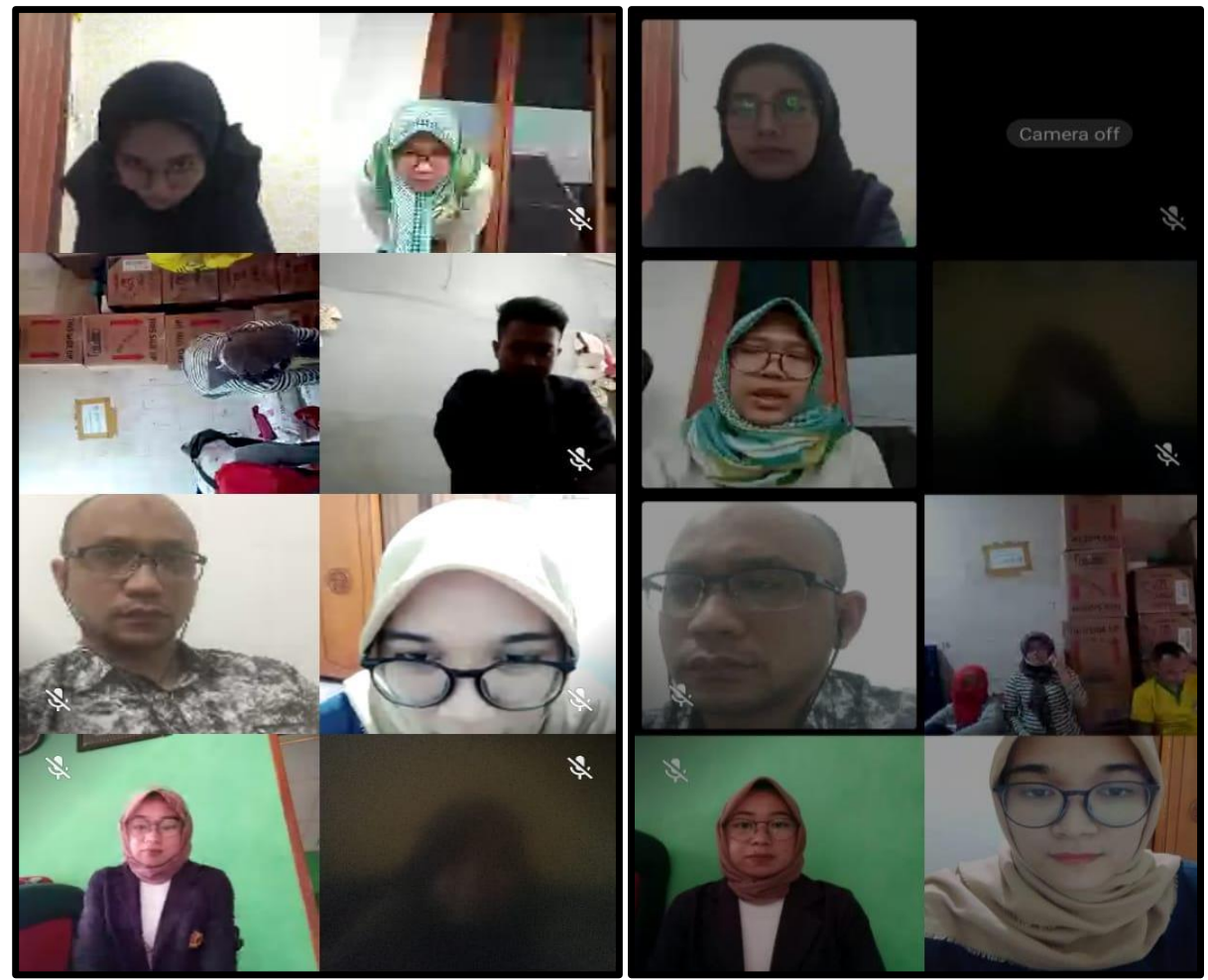

Gambar 2. Pelaksanaan Penyuluhan Melalui Zoom

\section{KESIMPULAN}

Kesimpulan yang bisa ditarik adalah hampir seluruh karyawan home industri peserta aktif dalam kegiatan penyuluhan yang menjadikan keberhasilan $100 \%$ peserta tidak meninggalkan ruangan zoom penyuluhan selama kegiatan berlangsung sampai selesai. Adanya perubahan peningkatan pemahaman pengetahuan warga mengenai tentang Kesehatan dan Keselamatan Kerja di home industri yang diukur dengan hasil pre-test dan pot tes juga tanya jawab tentang materi yang di berikan.

\section{DAFTAR PUSTAKA}

Alamsyah, Undang-Undang Republik Indonensia No. 1 Tahun 1970 tentang Keselamatan Kerja . online. 2004. Available from url: www.nakertrans.go.id.

CAHYATI, N. (2014). Peranan Kesehatan dan Keselamatan Kerja (K3) dalam Memperlancar Aktivitas Kerja Karyawan pada PT Sinar Sosro Pabrik Palembang (Doctoral dissertation, Politeknik Negeri Sriwijaya).

Darmawi, H. (2002). Manajemen risiko.

Dewanti, F. Q. (2019). Hubungan Paparan Debu Respirabel Dan Penggunaan Apd Masker Dengan Gangguan Faal Paru Pada Pekerja Home Industry Marmer Tulungagung (Doctoral Dissertation, Universitas Airlangga).

Dewi, I. A. M. S. (2019). MANAJEMEN RISIKO.

Djatmiko, R. D. (2016). Keselamatan dan kesehatan kerja. Deepublish.

Efendi, F \& Makhfudli. (2009). Keperawatan Kesehatan Komunitas: teori dan praktik dalam keperawatan. Ferry Efendi. 
Evadarianto, N., \& Dwiyanti, E. (2017). Postur Kerja Dengan Keluhan Musculoskeletal Disorders Pada Pekerja Manual Handling Bagian Rolling Mill. The Indonesian Journal of Occupational Safety and Health, 97 106.

Harjito, A. Martono.(2011). Manajemen keuangan, 50.

Hasibuan, A., Purba, B., Marzuki, I., Mahyuddin, M., Sianturi, E., Armus, R., \& Jamaludin, J. (2020). Teknik Keselamatan Dan Kesehatan Kerja. Yayasan Kita Menulis.

Kasidi, M. (2010). Manajemen Risiko. Ghalia Indonesia: Jakarta.

Kemenkes (2016). Kesehatan dan Keselamatan Kerja Komprehensif. Jakarta : Kementrian Kesehatan Republik Indonesia.

Kementerian Kesehatan Republik Indonesia. (2016). Kesehatan Dan Keselamatan Kerja. Pusdik SDM Kesehatan Badan Pengembangan Retrieved from http://bppsdmk.kemkes.go.id/pusdiksdmk/wpcontent/uploads/2017/08/Kesehatan-dan-Keselamatan-KerjaKomprehensif.pdf

Kurniawidjaja, L. M., 2010. Teori dan Aplikasi Kesehatan Kerja. Jakarta: Universitas Indonesia Press.

Kusuma, I. J., \& Darmastuti, I. (2010). Pelaksanaan program keselamatan dan kesehatan kerja karyawan PT. Bitratex Industries Semarang. Universitas Diponegoro: Semarang. http://eprints. undip. ac. id/15260/1/lbrahim Jati Kusuma. Pdf

Menteri Kesehatan Republik Indonesia. (2020,April). Surat Ederan Nomor HK.02.01/MENKES/216/2020 tentang Protokol Pencegahan Penularan Coronavirus disease (COVID-19 di Tempat Kerja. Jakarta : Menteri Kesehatan Republik Indonesia.

Nastiti, R. (2017). Analisis Faktor Yang Mempengaruhi Penggunaan Alat Pelindung Diri (Apd) Pada Pekerja Home Industry Kasur Kapuk Berdasarkan Theory Of Planned Behavior Di Desa Selorejo Bojonegoro (Doctoral Dissertation, Universitas Airlangga).

Salim, A. (1998). Asuransi dan Manajemen Risiko, PT. Raja Grafindo Persada, Jakarta.

Sedarmayanti. 2011. Tata Kerja dan Produktivitas Kerja. Bandung: Mandar Maju.

Silalahi, F. (1997). Manajemen Risiko dan Asuransi. Cetakan ke-1 (Jakarta: PT Gramedia Pustaka Utama, 1997).

Somad, Ismet. 2013. Teknik Efektif Dalam Membudayakan Keselamatan \& Kesehatan Kerja. Jakarta: Dian Rakyat.

Suma'mur, P. K. (1989). Ergonomi untuk produktivitas kerja. Haji Masagung.

Suryani, A. I., Ikhwansyah I., Eka L. M., 2013. Pengaruh Potensi Bahaya terhadap Risiko Kecelakaan Kerja di Unit Produksi Industri Migas PT. X Aceh. Jurnal Precure, [e-Journal] 1: pp. 34-42.

Tresnaningsih E. Kesehatan dan Keselamatan Kerja Laboratorium Kesehatan. Online. 2007. Available from url: www.depkes.go.id.

Wahyuni, N., Suyadi, B., \& Hartanto, W. (2018). Pengaruh Keselamatan Dan Kesehatan Kerja (K3) Terhadap Produktivitas Kerja Karyawan Pada Pt. Kutai Timber Indonesia. JURNAL PENDIDIKAN EKONOMI: Jurnal Ilmiah IImu Pendidikan, Ilmu Ekonomi Dan Ilmu Sosial, 12(1), 99. https://doi.org/10.19184/jpe.v12i1.7593

Wijaya, A., Panjaitan, T. W., \& Palit, H. C. (2015). Evaluasi Kesehatan dan Keselamatan Kerja dengan Metode HIRARC pada PT. Charoen Pokphand Indonesia. Jurnal titra, 3(1), 29-34. 